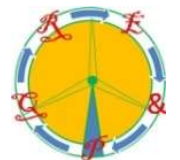

\title{
Real-Time Experimental Assessment of a New MPPT Algorithm Based on the Direct Detection of the Short-Circuit Current for a PV System
}

\author{
C. B. Nzoundja Fapi ${ }^{1,2}$, P. Wira ${ }^{2}$ and M. Kamta ${ }^{1}$ \\ ${ }^{1}$ LESIA Laboratory, \\ ENSAI, University of Ngaoundere, \\ P.O. Box: 455 Ngaoundere, Cameroon \\ ${ }^{2}$ IRIMAS Laboratory, \\ University of Haute Alsace, \\ 61 Rue Albert Camus, 68200 Mulhouse, France
}

E-mail: nzoufaclauber@yahoo.fr, patrice.wira@uha.fr,martin_kamta@yahoo.fr

\begin{abstract}
To substantially increase the efficiency of photovoltaic (PV) systems, it is important that the Maximum Power Point Tracking (MPPT) system has an output close to $100 \%$. This process is handled by MPPT algorithms such as Fractional Open-Circuit Voltage (FOCV), Perturb and Observe $(\mathrm{P} \& O)$, Fractional Short-Circuit Current (FSCC), Incremental Conductance (INC), Fuzzy Logic Controller (FLC) and Neural Network (NN) controllers. The FSCC algorithm is simple to be implemented and uses only one current sensor. This method is based on the unique existence of the linear approximation between the Maximum Power Point (MPP) current and the short-circuit current in standard conditions. The speed of this MPPT optimization technic is fast, however this algorithm needs to short-circuit the PV panel each time in order to obtain the short circuit current. This process leads to energy losses and high oscillations. In order to improve the FSCC algorithm, we propose a method based on the direct detection of the shortcircuit current by simply reading the output current of the PV panel. This value allows directly calculating the short circuit current by incrementing or decrementing the solar irradiation. Experimental results show time response attenuation, little oscillations, power losses reduction and better MPPT accuracy of the enhanced algorithm compared to the conventional FSCC method.
\end{abstract}

Keywords. Fractional Short Circuit Current (FSCC) algorithm, Maximum Power Point Tracking (MPPT), short-circuit current, Photovoltaic, experimental PV system.

\section{Introduction}

Over the last ten years, the use of renewable energy sources has increased substantially due to the drastic increase of the cost of fossil fuels and environmental pollution caused by the use of nuclear and fossil fuels [1], [2]. In this context, Photovoltaic (PV) energy systems offer a very competitive reliable solution. But electrical power efficiency of PV cells still remains low. In order to improve the efficiency of the PV panel, it is necessary to optimize the extraction of energy [3]-[5]. To achieve this task, the PV generator must operate at its Maximum Power Point (MPP). This constraint can be archieved by using a Maximum Power Point Tracking (MPPT) controller [6-8].

To ensure that the PV system will operate at its best efficiency, many MPPT algorithms have been developed. A hybrid version of Perturb \& Observe (P\&O), shortcircuit current and open-circuit voltage techniques with improved relations are derived in [9]. In [10] the authors compare performances and tracking accuracy between the Bisection Numerical Algorithm (BNA) based MPPT with Fractional Short-Circuit Current (FSCC) and Fractional Open-Circuit Voltage (FOCV). In [11], a conventional $\mathrm{P} \& \mathrm{O}$ method for various weather conditions by using the FSCC algorithm is proposed. To maximize the performance of the conventional INcremental Conductance (INC) method resulting from the sudden change of irradiance, the proposed method in [12] develops a new INC controller based on a fuzzy duty cycle change estimator with direct control. A new Fuzzy Logic Controller (FLC) for MPPT of PV systems is proposed in [13]. The authors use the Hill Climbing (HC) search method by fuzzifying the rules of such techniques and eliminate their drawbacks. A new digital control scheme for a standalone PV system using fuzzy logic and a dual MPPT controller is presented in [14].

The control strategy (indirect control and direct control), number of variables, implementation aspects (analogic or digital) and tracking are the four common ways to classify MPPT techniques [1]-[3]. The simplest methods are FSCC and FOCV which use the linearity of the short-circuit current or the open-circuit voltage with respect to the MPP current or voltage. However, these algorithms require an intermittent disconnection of the PV module to obtain the short-circuit current or the open circuit voltage. Thus, the overall efficiency of the PV plant is lower due to power losses during disconnection [10], [11]. The FSCC technique is easy to be implement because it requires only one current sensor. The FSCC technique requires periodic 
short-circuit current measurements to track the MPP and results in a temporary power loss [11].

This paper presents a new MPPT algorithm that takes the advantages of FSCC MPPT algorithm. The proposed MPPT method uses the direct detection of short circuit current by simply measuring the output current of the PV panel. This reading allows the direct calculation of the short-circuit current by incrementing or decrementing the solar irradiation.

To check the validity of the proposed algorithms, several tests with real-time weather conditions have been carried out. The electrical synoptic of the experimental configuration of the PV system is illustrated in Fig. 1. The acquisition unit measures the current and voltage of the PV panel and these signals are processed by a DS1104 control board to drive the DC-DC boost converter by means of a Pulse Width Modulation (PWM).

The paper is articulated as outlined below: The equivalent electrical model of a PV cell with a diode is described in Section II. Subsequently, the algorithms for searching for MPP are explained in Section III, focusing first on the FSCC MPPT algorithm and then on the proposed method. Section IV presents the implementation of the different algorithms and the results of the experimental tests. The conclusion is presented at the end of the document summarizing the salient points.

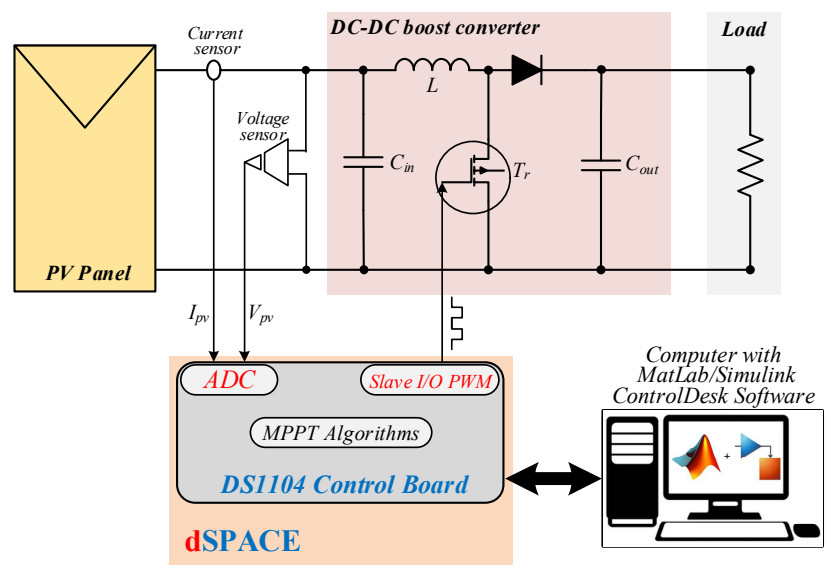

Fig. 1. Electrical synoptic scheme of experimental setup of the PV system.

\section{Equivalent electrical model of a pv cell}

The equivalent electrical model of a PV cell with a single diode is a circuit that consists of two resistors $\left(R_{p}\right.$ and $R_{S}$ ) and a diode that are presented in Fig. 2 [7], [15]. The equivalent model of the PV cell with one diode is preferred in this work because the number of iterations for the mathematical calculation of the current is less complex and generates fewer errors. It gives a faster result than the two diode model [7].

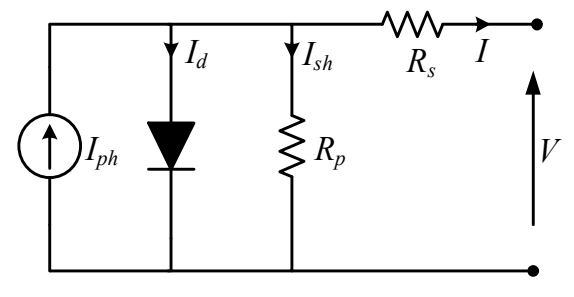

Fig. 2. Equivalent electric model of a PV cell.

Eq. (1) representing the PV cell generated current (I) is obtained by applying Kirchhoff's rules of the equivalent circuit represented by Fig. 2 . The current $(I)$ is given by:

$$
I=I_{p h}-I_{o}\left[\exp \left(\frac{q\left(V+R_{s} I\right)}{n k T N_{s c}}\right)-1\right]-\frac{V+R_{s} I}{R_{p}}
$$

where $V$ is voltage of the PV panel, $I_{p h}$ is the generated photocurrent, $R_{p}$ and $R_{s}$ are respectively the parallel and serial resistances, $q$ is the electron charge, $I_{o}$ is the diode reverse saturation current, $k$ is the Boltzmann constant, $n$ is the diode ideality factor, $N_{s c}$ is total number of series cells and $T$ is the surface cell temperature. The photocurrent $\left(I_{p h}\right)$ is given by:

$$
I_{p h}=\left[I_{s c}+k_{s c}\left(T-T_{r e f}\right)\right] G / G_{r e f}
$$

In this previous relation, $G$ is the irradiation, $I_{s c}$ is the short-circuit current, $k_{s c}$ is the temperature coefficient for the current, $T_{r e f}$ is the nominal temperature in Kelvin and $G_{r e f}$ is the nominal irradiation. The diode reverse saturation current $\left(I_{o}\right)$ is given by:

$$
I_{o}=\frac{\left[I_{s c}+k_{s c}\left(T-T_{r e f}\right)\right]}{\exp \left\{q\left[V_{o c}+k_{o c}\left(T-T_{r e f}\right)\right] / n k T N_{s c}\right\}-1}
$$

where $k_{o c}$ is the temperature coefficient for the voltage and $V_{o c}$ is the cell's open-circuit voltage at the nominal conditions.

In this paper, the parameters are the ones of the Solarex Solex FSM 145W-24 PV panel under the standard test condition (STC: $298.15 \mathrm{~K}$ and $1000 \mathrm{~W} / \mathrm{m}^{2}$ ) with a summary in Table I.

Table I. Electrical parameters of the Solarex Solex FSM $145 \mathrm{~W}-24$

\begin{tabular}{|l|c|c|}
\hline Parameters & Values & Symbols \\
\hline Maximum power $(W)$ & 145 & $P_{m p}$ \\
\hline Temperature coefficient of $I_{s c}(A / K)$ & 0.0065 & $k_{s c}$ \\
\hline Maximum Current $(A)$ & 4.2 & $I_{m p}$ \\
\hline Short-circuit current $(A)$ & 4.7 & $I_{s c}$ \\
\hline Maximum voltage $(V)$ & 34.4 & $V_{m p}$ \\
\hline Series cells & 72 & $N_{s c}$ \\
\hline Temperature coefficient of $V_{o c}(V / K)$ & -0.3609 & $k_{o c}$ \\
\hline Open-circuit Voltage $(V)$ & 43.5 & $V_{o c}$ \\
\hline Parallel cell & 1 & $N_{p}$ \\
\hline
\end{tabular}

To determine the MPP of the Solarex Solex FSM $145 \mathrm{~W}-24 \mathrm{PV}$ panel, the decisive step is to determine the power - voltage and current - voltage characteristics. $I-V$ and $P-V$ characteristics of solar photovoltaic modules under the STC are the basic requirements for monitoring 
the MPP using any of the MPPT techniques or algorithms. Therefore, the characteristic curves of the Solarex Solex FSM 145W-24 PV panel in Fig. 3 and Fig. 4 are simulated in the Matlab/Simulink environment.

For different weather conditions, the electrical characteristics of the PV cell are generally represented by the power versus voltage $\left(P_{p v}-I_{p v}\right)$ and current versus voltage $\left(I_{p v}-V_{p v}\right)$ curves. Fig. 3 shows that the opencircuit voltage $V_{o c}$ strongly decreases with the temperature but the short-circuit current $I s c$ increases slightly due to better absorption of light.

In Fig. 4, the open-circuit voltage $V_{o c}$ increases slightly when the short-circuit current $I_{s c}$ increases in an approximate linear way with irradiance and temperature.

For all PV systems, the output power is adjusted by using a MPPT algorithm to track the optimum power.

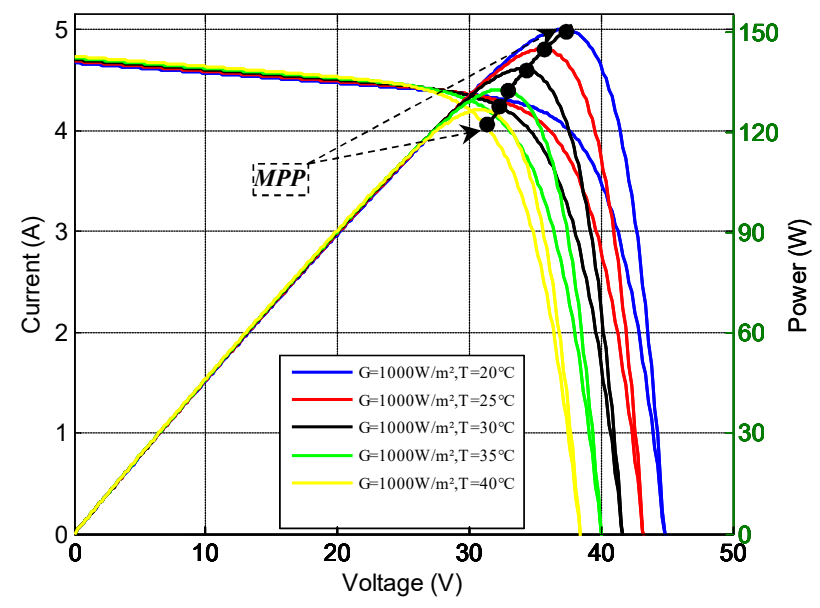

Fig. 3. Temperature effect on the current and power on the PV panel with of the Solarex Solex FSM 145W-24 parameters.

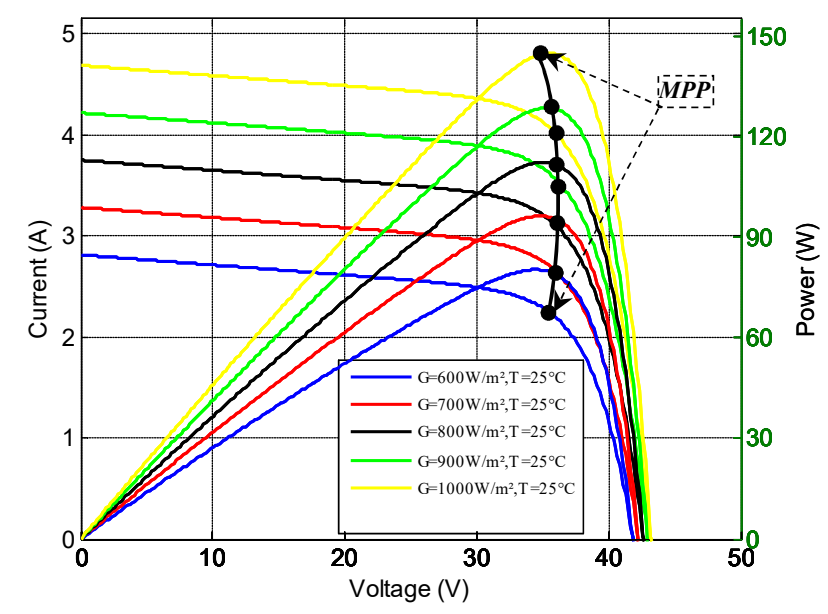

Fig. 4. Irradiation effect on the current and power on the PV panel with of the Solarex Solex FSM 145W-24 parameters.

\section{Enhanced FSCC MPPT algorithm}

For the PV system to operate at the MPP of their characteristics, there are specific control laws that meet this need. This command is named in the literature MPPT [1]-[5]. The principle of these methods is to seek the point of maximum power by keeping a good fit between the PV panel and the load to ensure the transfer of the maximum available power. The MPPT control is associated with a static converter to adapt the PV panel to the load so that the power generated corresponds to its maximum value and is transferred directly to the load.

\section{A. Conventional FSCC algorithm}

The process flow chart of the conventional FSCC algorithm is described by Fig. 5. It is based on the linear relationship between the short-circuit current $\left(I_{s c}\right)$ and the current at the MPP $\left(I_{m p p}\right)$ of the PV panel. The technique is simple and easy to be implemented [10], [11]. The expression of the linear relationship between $I_{s c}$ and $I_{m p p}$ is given by the following equation $[10,11]$ :

$$
I_{m p p}=K_{i} \times I_{s c}
$$

where $K_{i}$ is a constant of proportionality.

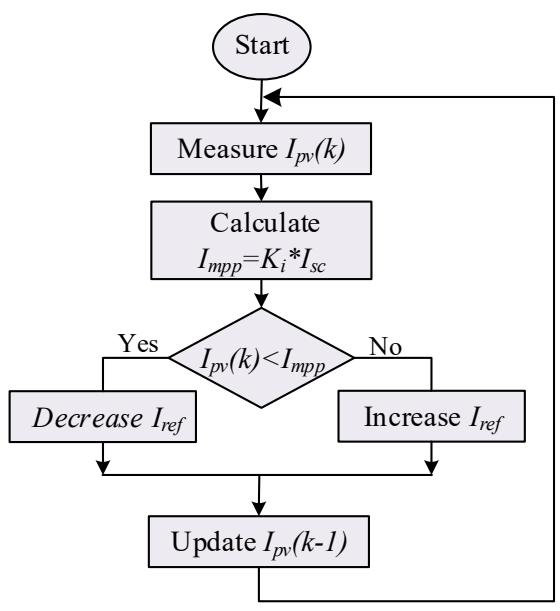

Fig. 5. The FSCC algorithm flowchart.

In Fig. 5, we can see that conventional FSCC algorithm needs to short-circuit the PV panel each time in order to obtain the short-circuit current. This process results in loss of power and approximate tracking of the MPP [10], [11].

\section{B. Proposed MPPT Method}

To improve the FSCC algorithm, the proposed algorithm is based on the direct detection of the shortcircuit current by simply reading the output current of the PV panel. The measured value will facilitate the direct calculation the short-circuit current by incrementing or decrementing the solar irradiation.

Eq. (5) represents the general expression used to estimate the short-circuit current for irradiance changes (see Fig. 3 and Fig. 4) to solve the PV panel short-circuit problems [10].

$$
I_{s c_{-} c a l}=\left(I_{s c} \times G\right) / G_{r e f}
$$

The proposed MPPT method begins by measuring the current $I_{p v}$ of the PV panel (blue loop in Fig. 6). Then, the variables $K_{i}$ and $K_{i i}$ are calculated simultaneously using Eq. (4) and Eq. (6) respectively.

$$
K_{i i}=I_{p v} / I_{s c}
$$


A first comparison is made between both variables. If the value is less than $\varepsilon$ (value defining the sensitivity of the system), then the program applies the FSCC algorithm.

If not, we calculate a new value of $I_{s c_{-} c a l}$ using Eq. (5) (red loop in Fig. 6). This equation makes it possible to estimate the value of the short-circuit current as a function of the solar irradiation. A new variable $K_{i i i}$ is calculated using Eq. (7) and is compared to $K_{i}$. If the difference is less than $\varepsilon$, then the program applies the FSCC algorithm.

$$
K_{i i i}=I_{p v} / I_{s c_{-} c a l}
$$

If not, we compare $K_{i i i}$ with $K_{i i}$. If the difference is less than zero, we increment the value of $G$ in Eq. (5). After that, the algorithm returns to the beginning of the calculation step of $I_{s c}$ cal .

If not, we decrement the value of $G$ in Eq. (5) and return to the beginning of the calculation step of $I_{s c_{-} \text {cal }}$. This process is repeated until the difference $K_{i i i}$ and $\bar{K}_{i}$ is less than $\varepsilon$. This algorithm is described by the diagram of Fig. 6.

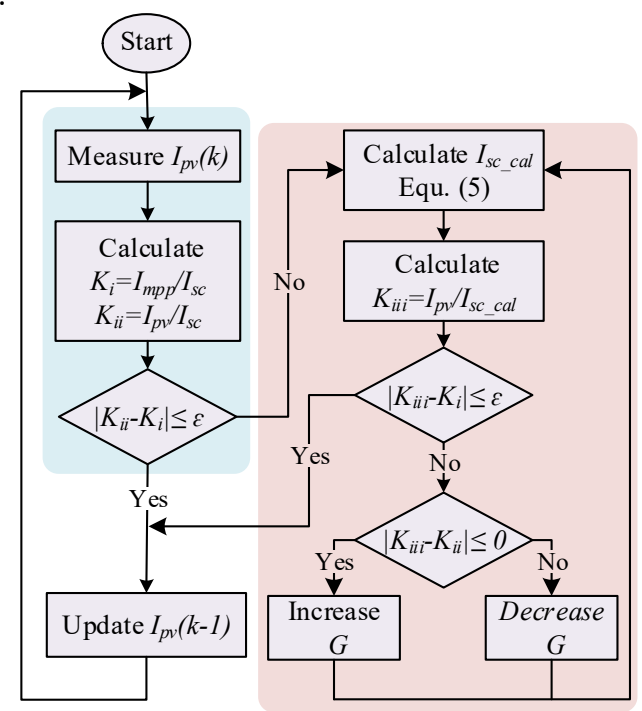

Fig. 6. The flowchart of the proposed technique.

\section{Experimental tests}

\section{A. Parameters for the evaluation of MPPT algorithms}

Some well-known parameters can evaluate the effectiveness of an MPPT algorithm and assess its performance, like the tracking efficiency given by Eq. (8), the ripple rate of Eq. (9), the average power given by Eq. (10), the response time and the implementation complexity. The above criteria are particularly appropriate for simulation tests [2], [4]-[5] but are less relevant in outside experiments which are subject to changing and random conditions. Nevertheless, simulations will never allow characterizing the full behavior of a PV panel and its power tracking strategy [8], [11].

In this paper, the MPPT methods described in Section III are tested and evaluated using real conditions of temperature and irradiance. The different measurements (voltage, current and power) are used to calculate the tracking efficiency, ripple rate, average power, and response time. These data are used to verify the performance of different MPPT methods.

The tracking efficiency $\eta$ is an important parameter in the MPPT algorithm. This value is calculated as follows:

$$
\eta=\frac{\int_{0}^{t} P_{\text {mppt }}(t) d t}{\int_{0}^{t} P_{\max }(t) d t} \times 100
$$

The ripple rate of the power $\tau_{o}$ is the ratio between the efficiency value and the average value of the ripple:

$$
\tau_{o}=\frac{P_{p v_{-} \text {ond }}}{P_{p v}},
$$

where $P_{p v_{-} \text {ond }}$ is the effective power of PV panel.

The average power $P_{m}$ is the PV output power under the control of MPPT over some period of time $T$. It is calculated as follows:

$$
P_{m}=\frac{1}{T} \int_{0}^{T} P_{m p p t}(t) d t
$$

The response time $\tau_{r}$ corresponds to the time needed to reach the new MPP value.

\section{B. Implementation aspects}

The experimental evaluation of the MPPT algorithms performance is verified by using the test bench that is illustrated in Fig. 7 (designed and implemented at the IRIMAS laboratory, located in the IUT of Mulhouse of the University of Haute Alsace in France). The test bench consists of the following elements.

A photovoltaic solar panel Solarex Solex FSM 145-24 is placed outside of the building. With a south-east orientation (The PV characteristics are given in Table I). TSL2591 and DHT11 sensors are used to record respectively irradiance and temperature.

The current and voltage sensors are used to acquire the current and voltage output of the PV panel. Both of these data are used as input variables for the MPPT controller to produce a Pulse Width Modulation (PWM) signal. The DC-DC converter, designed to operate in continuous inductive current mode (whose specifications are given in Table II), is directly connected to the PWM controller, which receives and amplifies the signal of the slave port I/O PWM of the DS1104 control board. This signal will be utilized to control the IGBT (electronic switch) of the DCDC boost converter, which in turn will shift the operating power to the MPP and achieve maximum operating efficiency. The load connected to the output of the DC-DC boost converter is a resistance of $120 \Omega$.

The DS1104 control board is connected to the computer equipment with the ControlDesk software and Matlab/Simulink software. The studied MPPT algorithms are implemented in Matlab/Simulink. Then, exploiting the features of the real-time interface toolbox (i.e., the RTI data block with a sampling frequency of $10 \mathrm{kHz}$ ) available in the Simulink libraries, the implemented MPPT algorithms are interfaced with the hardware.

The ControlDesk software allows managing the process hosted on the control board. It has been used as a system to first acquire, store the measured signals, then 
give access to the display of the respective curves and finally to facilitate the real-time analysis of the performance of the MPPT method in the control of the PV system. The hardware platform is permanently connected to the computer for interactive control, status monitoring and code download.

Table II. Parameters of DC-DC boost converter.

\begin{tabular}{|l|c|c|}
\hline Parameters & Values & Symbols \\
\hline Rated input current $(A)$ & 30 & $I_{\text {in }}$ \\
\hline Boost inductor $(m H)$ & 1.0 & $L$ \\
\hline Input filter capacitor $(\mu F)$ & 90 & $C_{\text {in }}$ \\
\hline Output filter capacitor $(\mu F)$ & 47 & $C_{\text {out }}$ \\
\hline Rated output current $(A)$ & 30 & $I_{\text {out }}$ \\
\hline Rated output voltage $(V)$ & 400 & $V_{\text {out }}$ \\
\hline Maximum Switching frequency $(\mathrm{KHz})$ & 50 & $f$ \\
\hline
\end{tabular}

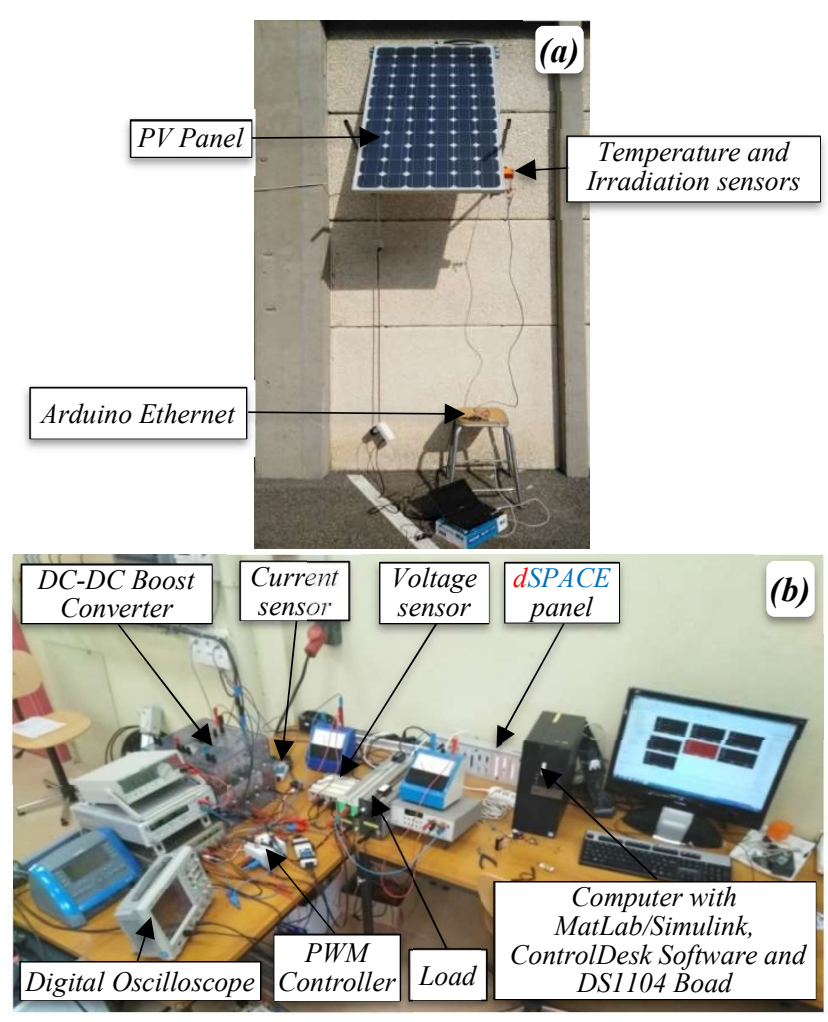

Fig. 7. The experimental test bench setup.

\section{Results}

In order to validate the effectiveness of the proposed technique, an experimental test bench is used to obtain the measured data acquisition. In Figures 8 and 9, the solar irradiation and the temperature recorded by their respective sensors on Monday 8 September 2018 between 15:00 pm and 15:04 pm local time in France are show.

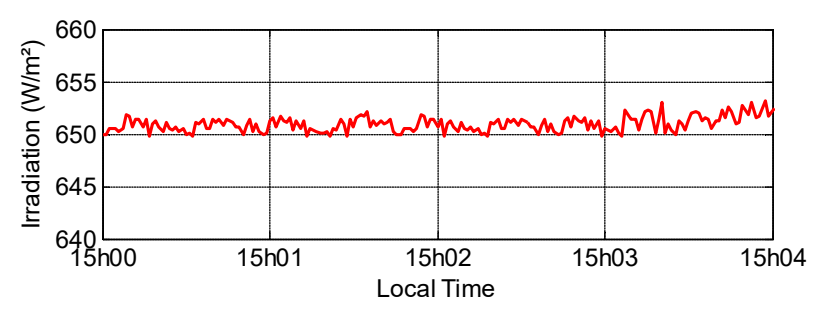

Fig. 8. Irradiation values during the experiment.

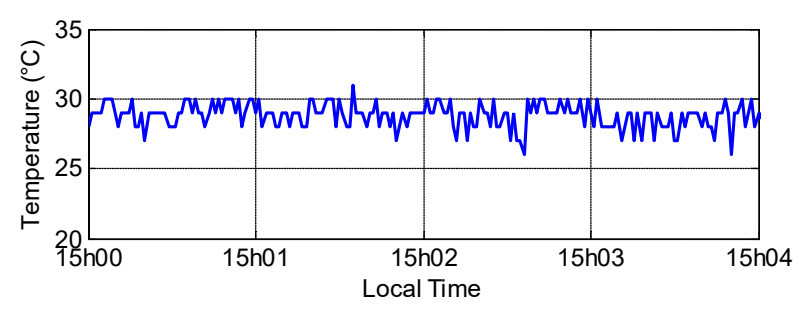

Fig. 9. Temperature values during the experiment.

The experimental results of transient and steady-state conditions are stored by using the ControlDesk software. Then, they are used to validate the effectiveness of the proposed method. A comparison between the classic FSCC MPPT algorithm and the proposed MPPT method are presented in Figures 10, 11 and 12. These figures present the experimental results of the voltage, current and the power of the PV panel of both algorithms. The results demonstrate that the improved MPPT controller achieves an optimal work cycle with a shorter stabilization time and produces more power because steady-state oscillations are lower.

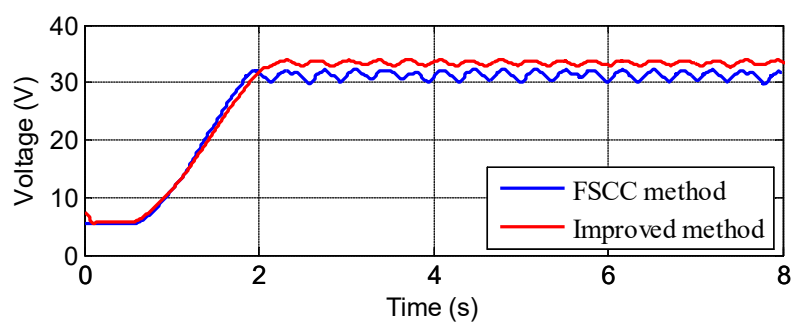

Fig. 10. Experimental curves of $V_{p v}$ obtained with the FSCC and the proposed method.

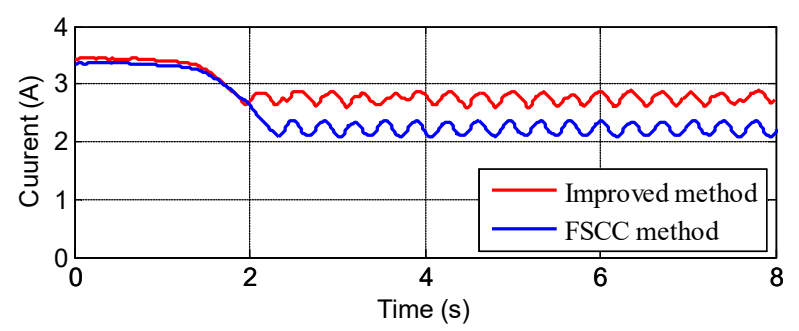

Fig. 11. Experimental curves of $I_{p v}$ obtained with the FSCC and the proposed method.

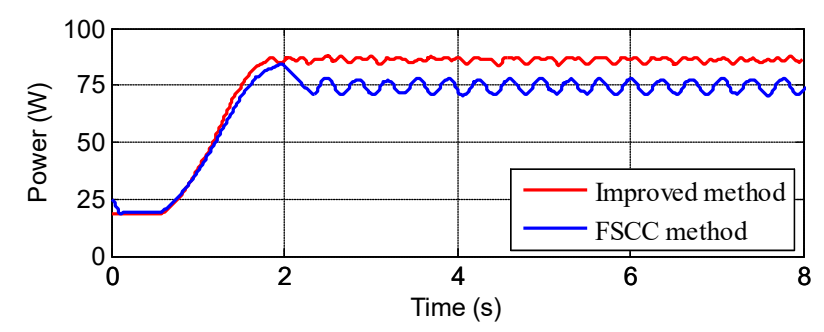

Fig. 12. Experimental curves of $P_{p v}$ determined with the FSCC and the proposed method.

Table III presents the results obtained with the MPPT algorithms, i.e., the conventional and the enhanced FSCC approaches. Eq. (8), Eq. (9) and Eq. (10) have been respectively used to calculate different performance indications like the tracking efficiency, ripple rate and average power. Performance indications in Table III clearly shows the attenuation of the response time, reduced 
oscillations, a reduction of the power losses and an accurate tracking of the MPP of the enhanced algorithm compared to the conventional FSCC method.

Table III. Performance and configuration comparison of the two MPPT methods with $\mathrm{T}=29^{\circ} \mathrm{C}$ and $\mathrm{G}=651 \mathrm{~W} / \mathrm{m}^{2}$.

\begin{tabular}{|l|c|c|}
\hline Parameters & $\begin{array}{c}\text { FSCC MPPT } \\
\text { algorithm }\end{array}$ & $\begin{array}{c}\text { Improved MPPT } \\
\text { algorithm }\end{array}$ \\
\hline Average power $P_{m}(W)$ & 75 & 85 \\
\hline $\begin{array}{l}\text { Ripple rate of the } \\
\text { power } t_{o}(W)\end{array}$ & 0.7 & 0.2 \\
\hline Efficiency $\eta(\%)$ & 90.75 & 98.47 \\
\hline Response time $\tau_{r}(s)$ & 1.1 & 0.7 \\
\hline $\begin{array}{l}\text { Implementation } \\
\text { complexity }\end{array}$ & Low & Medium \\
\hline $\begin{array}{l}\text { Initial setting } \\
\text { parameters }\end{array}$ & 1 parameter & 2 parameters \\
\hline Required sensors & Current & $\begin{array}{c}\text { Current, } \\
\text { Irradiance }\end{array}$ \\
\hline
\end{tabular}

\section{Conclusion}

Maximum Power Point Tracking (MPPT) algorithms are used to extract the maximum power in photovoltaic systems in order to improve their energy efficiency. An improved MPPT algorithm has been proposed in this study for this purpose. An improved MPPT algorithm has been proposed. The enhanced MPPT algorithm has been developed to solve the problems of traditional FSCC method. Indeed, the new algorithm is based on the direct detection of the short circuit current by simply measuring the output current of the PV panel. This measure leads to the direct calculation of the short-circuit current by the latest estimation of irradiance changes. The technique has been experimented and tested under real weather conditions. The experimental implementation has been designed with Matlab/Simulink and allows comparing the performances of the improved FSCC algorithm to the conventional one by calculating their tracking efficiency, average power, response time and ripple rate. In changing conditions, the proposed algorithm offers better precision and efficiency than that of the traditional FSCC MPPT technique.

\section{Acknowledgment}

The authors are grateful to the Foundation Pierre and Jeanne Spiegel for its generous financial support for this work.

\section{References}

[1] B. Subudhi and R. R. Pradhan. "A comparative study on maximum power point tracking techniques for photovoltaic power systems", IEEE Transactions Sustainable Energy, vol. 4, no. 1, pp. 89-97, 2013.

[2] C. B. Nzoundja Fapi, P. Wira, M. Kamta, A. Badji and H. Tchakounte, "Real-time experimental assessment of Hill Climbing MPPT algorithm enhanced by estimating a duty cycle for PV system", International Journal of Renewable Energy Research (IJRER), vol. 9, no. 3, pp. 1180-1189, 2019.
[3] M. A. Husain, A. Tariq, S. Hameed, M. S. B. Arif and A. Jain, "Comparative assessment of maximum power point tracking procedures for photovoltaic systems", Green Energy \& Environment, vol. 2, pp. 5-17, 2017.

[4] M. Danandeh and S. M. Mousavi, "Comparative and comprehensive review of maximum power point tracking methods for PV cells", Renewable and Sustainable Energy Reviews, vol. 82, pp. 2743-2767, 2018.

[5] A. Belkaid, I. Colak and K. Kayisli, "A Comprehensive study of different photovoltaic peak power tracking methods", 6th International Conference on Renewable Energy Research and Applications (ICRERA), San Diego, USA, pp. 1073-1079, 5-8 Nov. 2017.

[6] A. Blorfan, G. Sturtzer, D. Flieller, P. Wira and J. Mercklé, "An adaptive Control Algotithm for Maximum Power Point Traking for Photovoltaic Energy Conversion Systems - A comparative Study", International Review of Electrical Engineering (IREE), vol 9, no. 3, pp. 559-565, 2014.

[7] M. G. Villalva, J. R. Gazoli and E. R. Filho, "Comprehensive Approach to Modeling and Simulation of Photovoltaic Arrays", IEEE Transactions on Power Electronics, vol. 24, no. 5, pp. 1198-1208, 2009.

[8] R. Boukenoui, M. Ghanes, J. P. Barbot, R. Bradai, A. Mellit and H. Salhi, "Experimental assessment of Maximum Power Point Tracking methods for photovoltaic systems", Energy, vol. 132, pp. 324-340, 2017.

[9] A. F. Murtaza, M. Chiaberge, F. Spertino, U. T. Shami, D. Boero and M. D. Giuseppe, "MPPT technique based on improved evaluation of photovoltaic parameters for uniformly irradiated photovoltaic array", Electric Power Systems Research, vol. 145, pp. 248-263, 2017.

[10] M. M. Shebani, T. Iqbal, and J. E. Quaicoe, "Comparing Bisection Numerical Algorithm with Fractional Short Circuit Current and Open Circuit Voltage Methods for MPPT Photovoltaic Systems", IEEE Electrical Power and Energy Conference (EPEC), Ottawa, Canada, pp.1-5, 12-14 Oct., 2016.

[11] H. A. Sher, A. F. Murtaza, A. Noman, K. E. Addoweesh, K. Al-Haddad, and M. Chiaberge, "A New Sensorless Hybrid MPPT Algorithm Based on Fractional Short-Circuit Current Measurement and $\mathrm{P} \& \mathrm{O}$ MPPT", IEEE Transactions on Sustainable Energy, vol. 6, no. 4, pp. 1426-1434, 2015.

[12] T. Radjai, L. Rahmani, S. Mekhilef and J. P. Gaubert, "Implementation of a modified incremental conductance MPPT algorithm with direct control based on a fuzzy duty cycle change estimator using dSPACE", Solar Energy, vol. 110, pp. 325-337, 2014.

[13] B. N. Alajmi, K. H. Ahmed, S. J. Finney, and B. W. Williams, "Fuzzy-Logic-Control Approach of a Modified Hill-Climbing Method for Maximum Power Point in Microgrid Standalone Photovoltaic System", IEEE Transactions on Power Electronics, vol. 26, no. 4, pp. 1022-1030, 2011.

[14] N. A. Ahmad and R. Dhaouadi, "Efficiency optimization of a DSP-based standalone PV system using fuzzy logic and dual-MPPT control", IEEE Transactions on Industrial Informatics, vol. 8, no. 3, pp. 573-584, 2012.

[15] C. B. Nzoundja Fapi, P. Wira and M. Kamta, "A Fuzzy Logic MPPT Algorithm with a PI Controller for a Standalone PV System under Variable Weather and Load Conditions", IEEE International Conference on Applied Smart Systems (ICASS), Medea, Algeria, pp. 1-6, 24-25 Nov. 2018 